\title{
NEUROCIÊNCIAS E O CONCEITO DE CULPABILIDADE NO DIREITO PENAL1
}

\author{
NEUROSCIENCE AND THE CRIMINAL CONCEPT OF CULPABILITY
}

\section{HIRNFORSCHUNG UND STRAFRECHTLICHER SCHULDBEGRIFF}

É professor catedrático de Direito Penal, Processo Penal e Teoria do Direito na Universidade Johann Wolfgang Goethe-Universität Frankfurt am Main.

\begin{abstract}
Resumo
O autor analisa quais consequências as descobertas das neurociências trazem para o Direito penal, especialmente para o seu conceito de culpabilidade e, também, em última análise, para a própria concepção de Direito, que temos atualmente. Nesse sentido, aborda o conceito penal de culpabilidade, como ele é compreendido a partir da perspectiva de livre arbítrio e das concepções normativas, examinando também as opções que os penalistas podem adotar para enfrentar as teses neurocientíficos.
\end{abstract}

Palavras-chave: Direito Penal - Neurociências - Livre arbítrio Culpabilidade - Determinismo

\begin{abstract}
The author analyzes what are the consequences that the discoveries from the neuroscience bring to criminal law, especially to its concept of culpability and, ultimately, to the very conception of Law, that we have today. In this sense, it addresses the criminal concept of culpability, as it is understood from the perspective of free will and from the normative conceptions. The author also studies the options that criminal scholars can adopt to face neuroscientists theses.
\end{abstract}

Key-word: Criminal Law - Neuroscience - Free Will - Culpability Determinism

\footnotetext{
${ }^{1}$ Publicado orginalmente como: "Hirnforschung und strafrechtlicher Schuldbegriff", em Kritische Justiz Vol. 39, n. 2 (2006), pp. 116-133. Tradução do original em alemão por Rodrigo Leite Ferreira Cabral, Paulo César Busato e Letícia da Lozzo.
} 


\section{POR QUE APENAS O DIREITO PENAL?}

No atual debate sobre as possíveis consequências das novas descobertas das neurociências, o Direito penal tem um inegável papel de destaque, especificamente em relação ao conceito penal de culpabilidade. Renomados cientistas alemães, tais como Wolf Singer, Gerhard Roth ou Hans Markowitsch criticam o conceito de culpabilidade apresentado pelo Direito penal, sobretudo o conceito de pena culpável (Schuldstrafe), adotando, para tanto, um determinismo forte. Eles defendem que, se nossas escolhas e ações são absolutamente pré-determinadas por processos causais neurológicos, não sobra espaço para a liberdade de vontade - e quando a vontade não é livre, não é possível responsabilizar-se o agente pela prática de um delito; pelo menos não no sentido usual de que ele, em virtude de sua vontade, poderia ter, na mesma situação, agido de outro modo, de forma a ter evitado a prática criminosa. Com base nessas concepções, os cientistas fundamentam a rejeição da culpabilidade penal e da reprovação pela culpabilidade, substituindo-as pela ideia de medida de segurança ou, até onde permitam os conhecimentos médicos, por intervenções e terapias da neuromedicina. Wolf Singer, entretanto, recomenda apenas o uso de uma nova terminologia para o Direito penal, propondo o uso da palavra "responsabilidade". Sem embargo, o que ele realmente quer dizer é "periculosidade"2.

Os neurocientistas, ao colocarem em dúvida, de forma tão radical, a liberdade da pessoa, acabam por questionar não apenas o conceito de culpabilidade e de pena, mas sim o próprio conceito de Direito, como um todo. Isso pode ser demonstrado por um simples exemplo. A partir dessa concepção, não é apenas o delinquente que não escolhe suas ações, mas também não escolhem os juízes que decidem sobre elas. De tal maneira, o seu julgamento não seria mais o resultado de uma decisão livre - apesar de juridicamente vinculada - e, nesse sentido, responsável. Decorria, isso sim, uma vez mais, de um curso causal, sobre o qual o juiz não teria responsabilidade alguma. Esse exemplo deixa claro que - antes de qualquer discussão a respeito da liberdade de vontade, como um requisito necessário ou desnecessário para determinadas áreas do Direito ou institutos legais - existe uma premissa jurídica fundamental que é colocada em questão: o Direito pressupõe que os destinatários de uma norma possam, por si

${ }^{2}$ Wolf Singer, Grenzen der Intuition: Determinismus oder Freiheit, in: Rainer Maria Kiesow/ReginaOgorek/Spiros Simitis (Org.), Summa. Festschrift für Dieter Simon zum 70. Geburtstag, Frankfurt am Main 2005, p. 529 e ss (p. 537). 
sós, dirigir e controlar seu comportamento de acordo com ela, de modo que consigam seguir a lei com base em suas próprias ponderações e decisões. Em suma, uma característica constitutiva do Direito é, sobretudo, a liberdade individual das pessoas de decidirem, por elas mesmas, seguir ou infringir a norma. Sem essa premissa, a conduta de cada indivíduo teria que ser observada e monitorada de forma extensa e completa, por meio de um largo aparato de controle, com um programa orientado por determinadas condicionantes e técnicas de manipulação social. No contexto dessa alternativa é surpreendente que o debate em si sobre as consequências da neurociência para a liberdade se restrinja exclusivamente ao Direito penal.

\section{CULPABILIDADE PENAL COMO UMA FORMA DISCUTíVEL DE ATRIBUIÇÃO}

Apesar desses desafios apresentados pelos neurocientistas, os penalistas não reagiram de modo uniforme. Isso porque, o próprio conceito penal de culpabilidade é controverso, sobretudo quanto a pressupor esse conceito ou não liberdade de vontade. Diante disso, nas Ciências Penais, com o objetivo de delinear possíveis consequências para o Direito penal, constantemente são desenvolvidas novas teorias, com posições afirmativas, negativas ou agnósticas em relação à liberdade da vontade ${ }^{3}$. À luz desses esforços, é desanimador concluir que, em quase nenhum sistema penal do mundo, conseguiu-se achar uma definição juridicamente consistente do conceito de culpabilidade. Em nenhum lugar encontra-se uma frase como: "a culpa do agente é dada quando...". É verdade que a culpabilidade penal, em um sentido abrangente, pressupõe, dentre outras coisas, a intencionalidade do agressor, que é determinada em lei, como dolo e culpa. No entanto, nenhuma concepção definitiva de culpabilidade pode ser encontrada, que não esteja imune a exceções imprevisíveis. Na contínua controvérsia do Direito penal alemão a respeito da delimitação entre dolo eventual e

\footnotetext{
${ }^{3}$ Veja-se: Reinhard Merkel, in: Festschrift für Lothar Philipps; Günther Jakobs, Individuum und Person. Strafrechtliche Zurechnung und die Ergebnisse moderner Hirnforschung, ZStW 2005, p. 247 e ss.; Thomas Hillenkamp, Strafrecht ohne Willensfreiheit? Eine Antwort auf die Hirnforschung, JZ 60, 2005, p. 313 e ss.; Björn Burkhardt, Was ist es, ein Mensch zu sein?, in: Jörg Arnold et alli. (org.), Festschrift f. A. Eser z. 70. Geburtstag, München 2005, p. 77 e ss.; Klaus Lüderssen, Ändert die Hirnforschung das Strafrecht?, in: Christian Geyer (Org.), Hirnforschung und Willensfreiheit, Frankfurt am Main 2004, p. 98 e ss.; Anja Schiemann, Kann es einen freien Willen geben? Risiken und Nebenwirkungen der Hirnforschung für das deutsche Strafrecht, NJW 2004, p. 2056 ss. Sobre a posição da doutrina nos manuais e comentários, cf.: Claus Roxin, Strafrecht Allgemeiner Teil, vol. 1, 4. ed. München 2006, § 19 $\mathrm{Nm}$. 43 e ss.; Wolfgang Schild, in: Nomos-Kommentar Strafgesetzbuch, vol. 1, 2. ed. Baden-Baden 2005, § $20 \mathrm{Nm}$. 7-8.
} 
culpa consciente (correspondente à recklessness e à negligence do common law) mostra-se que, também aqui, a delimitação negativa de um conceito prevalece sobre os casos excepcionais. Isso se aplica, sobretudo, àqueles elementos do conceito da culpabilidade que dizem respeito ao seu próprio núcleo essencial, nomeadamente aqueles relacionados à reprovabilidade individual na formação da vontade, ou seja, a culpabilidade como categoria sistemática, em sentido estrito. Aqui encontram-se ainda definições negativas: um agente age com culpabilidade quando certas exceções não estiverem presentes. No Direito penal alemão elas são sobretudo: a falta de maturidade (menor de 14 anos de idade) ou a incapacidade causada por doença, que impede conhecer o caráter ilícito da ação ou agir de acordo com esse entendimento (§§ 19, 20 - Código Penal Alemão - StGB), a falsa compreensão do injusto em caso de inevitabilidade de erro (erro de proibição, §17 StGB), as circunstâncias especiais do fato que tornam a desobediência ao Direito ou a violação a um bem jurídico, pelo menos, compreensível (estado de necessidade exculpante - § 35 StGB - excesso de legítima defesa §33 StGB), assim como, em geral, a inexigibilidade de conduta conforme o direito (por exemplo, caso de colisão de deveres, nos delitos omissivos). Mais uma vez, essas normas, que determinam quando se exclui a culpabilidade, não contêm um catálogo fechado, nem gozam de um conceito que tenha uma validade universal, que transcende o tempo e o espaço. Muito pelo contrário, esses conceitos variam, em grande medida, histórica e culturalmente. Nesse sentido, o estado de necessidade exculpante, em alguns ordenamentos jurídicos (por exemplo, no common law angloamericano), é reconhecido como uma simples causa de diminuição de pena, mantendose a culpabilidade intacta, assim como a idade da imputabilidade penal varia de ordenamento jurídico para ordenamento jurídico, inclusive no âmbito da Europa ocidental e, algumas vezes, de forma substancial.

A vantagem dessas definições negativas é que o legislador não precisa se comprometer com um determinado significado de culpabilidade, com uma resposta potencialmente problemática à questão do livre arbítrio. Além dessa razão pragmática, existe outra provavelmente ainda mais profunda. Assim, como na ausência de uma excludente de culpabilidade ou de um fundamento exculpante, afirma-se a culpabilidade criminal, sem a necessidade de ulterior fundamentação, parece razoável pressupor que, em Direito penal, todo delinquente é culpável, desde que não sofra de uma causa excludente de culpabilidade ou exculpante, de natureza interna ou externa. No processo penal, o acusado é considerado como dotado de culpabilidade, sem a necessidade de 
provas nesse sentido, a menos que existam circunstâncias especiais que tornem essa suposição duvidosa. A técnica dos legisladores penais (e também dos precedentes no common law) consiste assim na utilização de um modelo de regra-exceção, em que a prática jurídico-penal opera de acordo com um procedimento de exceções e refutações: a culpabilidade penal é "o que resta", quando nenhuma das referidas exceções legais se fazem presentes. Nesse sentido, H. L. A. Hart interpretou a responsabilidade penal como uma atribuição refutável ${ }^{4}$. Um agente é culpável, quando ele não consegue refutar prima facie essa atribuição, com base em uma exceção. Desse modo, costuma-se dizer que a formação da vontade relativamente ao fato é atribuível individualmente ao agente, de acordo com a sua correspondente culpabilidade ${ }^{5}$.

\section{CULPABILIDADE PENAL COMO NORMALIDADE PRESSUPOSTA}

O que decorre dessa simples descoberta para o conceito de culpabilidade do Direito penal? Que o Direito penal e o Sistema Jurídico-penal operam de acordo com um tipo de normalidade pressuposta, que pode ser confrontada com base em exceções. A regra é que, o que se encontra dentro da normalidade da população em um determinado período de tempo, é considerado "normal". Quem não sofre de um dos mencionados déficits ou quem, no momento da ação delitiva, não se encontra em uma situação extrema de ameaça, é considerado capaz de agir conforme o Direito e evitar a violação aos bens jurídicos. Quando a maioria dos destinatários da lei consegue, em circunstâncias normais, orientar seu comportamento de acordo com ela, conseguirá, também, dessa forma orientar-se o indivíduo. A maioria eleva as habilidades médias da população na escala geral, que servirá de medida para o delinquente individual6: isso se aplica tanto às habilidades cognitivas e volitivas em geral, quanto à diferenciação entre aquelas situações de conflito, que não são mais toleradas, nas quais mal se consegue superar, sem a violação a bens jurídicos alheios. Se o acusado está dentro

${ }^{4}$ H.L.A. Hart, The Ascription of Responsibility and Rights, in: Proceedings of the Aristotelian Society 49 (1948/49), p. 171 ss. Hart formulou este ensaio sob uma posição de crítica, que, no entanto, se voltou principalmente contra o uso descritivo do conceito de ação; Cf. H.L.A Hart, Punishment and Responsibility, 2. ed. Oxford 1988, p. V. Zur Kritik ss.: George Pitcher, Handlung und Verantwortung bei Hart, e: Peter Geach, Der Askriptivismus, ambos in: Georg Meggle (Org.), Analytische Handlungstheorie, vol. 1, Frankfurt am Main 1977, p. 225 ss. e p. 239 ss. Sobre as consequências no Direito penal das teses adscritivas de Hart, cf. Lothar Kuhlen, Die Objektivität von Rechtsnormen, Frankfurt am Main entre outros, 1978, pp. 91-107.

${ }^{5}$ Herbert Tröndle/Thomas Fischer, Strafgesetzbuch und Nebengesetze, Kommentar, 52. Ed. München 2005 , Vor $\S 13, \mathrm{Nm} .28$.

${ }^{6}$ Nesse sentido, por exemplo, Günter Stratenwerth/Lothar Kuhlen, Strafgesetzbuch Allgemeiner Teil I, 5. ed. Köln/Berlin/München 2004, § 10 Nm. 4. 
do standard, ele é culpável, caso contrário, não haverá culpabilidade e não poderá ele ser punido. É assim que nos comportamos no dia a dia. Se alguém pisar em nossos pés, o consideramos espontaneamente culpado e acusamos o seu comportamento. Apenas quando duvidamos, é que indagamos se talvez houvesse um motivo para que isso ocorresse, ou se estava presente alguma condição excepcional, que nos faria retirar a reprovação. Isso significa, porém, que nós normalmente culpamos as pessoas por suas ações. Somente quando alguém responde com um pedido de desculpas, quando vemos que a pessoa tropeçou ou, com maior razão, quando verificamos que ela se encontra sob um severo e manifesto transtorno mental, modificamos nossa opinião. A pessoa não tinha a intenção, ela não podia fazer nada a respeito. Verificase, então, que existem circunstâncias nas quais, em determinado momento, a competência média esperada, de podermos controlar nossos movimentos corporais, é comprometida de forma severa. Essa auto-evidência social de atribuição mútua de responsabilidade, da qual somente nos desviamos em fundamentados casos excepcionais, rege, também, o Direito penal: "se a culpa, como regra (...) não demanda nenhuma justificativa especial, é porque a responsabilidade do homem é compreendida por sua própria conduta, salvo se incidirem determinadas exceções" 7 .

\section{O QUE SIGNIFICA A PRESSUPOSIÇÃO DE NORMALIDADE?}

Por melhor que essa prática possa funcionar nas interações sociais quotidianas, verifica-se que, quando casos difíceis exigem, por um momento, um distanciamento e demandando que se busque os seus fundamentos, a certeza de uma rotina cotidiana confortável acaba se perdendo. Frequentemente fica em aberto, se e como essa generalizada pressuposição de normalidade pode ser justificada e quais outras suposições a justificam, particularmente quais conclusões podem ser desenhadas a favor ou contra um conceito de culpabilidade baseado no livre arbítrio.

Portanto, não se pode simplesmente inferir da referida lista de exceções, que elas simplesmente se limitam a um conteúdo oposto à normalidade, com a qual operamos diariamente toda atribuição de responsabilidade. Assim, parece que nós simplesmente sabemos quando não podemos presumir essa normalidade (por exemplo, diante de uma enfermidade mental), mas nós não conhecemos todas as condições necessárias e suficientes para essa própria pressuposição de normalidade. 
Ademais, permanece aberta a questão se a pressuposição de normalidade está subordinada a uma regularidade estatística ou normativa, ou mesmo às duas. Uma assunção de regularidade estatística sugere uma constatação empírica de que, sob condições sociais e políticas normais (ou seja, em situações em que não exista desigualdade social extrema, nem conflitos sociais sérios, nem repressão política massiva, em que o Estado apoia práticas criminosas), a maior parte da população comporta-se, em média, de acordo com o Direito, apesar das pesquisas criminológicas sobre cifras ocultas e os conhecimentos sobre a seletividade penal indicarem que o número de práticas delitivas é muito superior aos casos abrangidos pela estatística policial e criminal. No entanto, é evidente que, pelo menos, as normas elementares do Direito, como um todo e em grande escala, são seguidas. Ademais, pouco se pode falar contra a pressuposição de que isso ocorre, principalmente de forma voluntária, não sendo, portanto, resultado de uma adaptação externa, apesar da existência de uma rejeição interna - pelo menos enquanto nem o terror aberto ou o controle estatal total ou medidas amplas de prevenção tomem conta da psique dos destinatários da norma, impondo condicionamentos e disciplinamentos aos cidadãos. Nesse sentido, o conceito penal de culpabilidade está fundado na experiência de que a maioria dos destinatários da norma tem um mínimo de discernimento e autocontrole, para que a pressuposição de culpabilidade possa, a esse respeito, estar empiricamente justificada. No entanto, ela em, pelo menos, duas maneiras, também tem um sentido normativo:

(I) O uso de uma específica capacidade média como critério distintivo para a atribuição da culpabilidade penal é, em si, uma decisão fundamentada normativamente. Isso fica claro quando o legislador tem que decidir em quais condições se faz presente a capacidade de culpabilidade ( $\$ 20 \mathrm{StGB}$ ), assim como quando tem que estabelecer onde deve estar o limite entre o normal e o anormal. Ainda no primeiro elemento da culpabilidade, configurado pelas condições necessárias de capacidade de culpabilidade, os assim chamados componentes biológicos-psicológicos ${ }^{8}$, não são apenas os conhecimentos médicos sobre as enfermidades ou distúrbios corporais e psicológicos que devem ser levados em conta. Não são só eles que devem ser tão profundos, a ponto de afetar o discernimento necessário para o segundo estágio, consistente na capacidade de entendimento e autodeterminação. O nível de conhecimento da medicina encontra na política criminal, orientada normativamente que decide de acordo com seus próprios critérios -, quais condições médicas são tidas

${ }^{8}$ Lackner/Kühl, Strafgesetzbuch Kommentar, 25. Aufl. München 2004, § 20 Nm. 1 p. 
como relevantes para a identificação da capacidade de culpabilidade. Isso pode ser exemplificado pela discussão que ocorreu durante o último debate sobre a reforma de 1975, no Comitê do Parlamento alemão, sobre se o primeiro elemento do §20 StGB deveria ser um buraco de agulha ou uma grande porta de entrada. Se a porta do primeiro elemento fosse demasiadamente aberta, haveria o risco de um rompimento de barreiras e, de tal maneira, como decorrência dessa interpretação, mais delinquentes poderiam ser beneficiados pela falta de capacidade de culpabilidade, do que o esperado, a partir de uma valoração político-criminal. Por exemplo, a pena poderia perder seu efeito de prevenção geral, caso potenciais criminosos pudessem esperar serem declarados, de qualquer modo, inimputáveis ${ }^{9}$. Richard Lange resumiu, com precisão, esse receio: O primeiro elemento se tornaria então uma "porta de entrada para os associais" ${ }^{10}$. Diante dessa impressão, o primeiro elemento do $\S 20$ da StGB foi finalmente formulado de modo que permanecesse uma espécie de buraco de agulha. Como resultado, é possível concluir que, uma afirmação empírica sobre uma enfermidade mental, não é suficiente para, sozinha, responder a pergunta sobre a incapacidade de culpabilidade penal. Mesmo diante de uma profunda destruição social, decorrente de iniquidades sociais tão graves que interfiram na psique do delinquente, em que ele ainda que possa entender, mas dificilmente autodeterminar de acordo com esse entendimento - não há dúvidas de que a sua liberdade pode, efetivamente, ter sido limitada. No entanto, ainda assim ele é tratado como imputável, precisamente porque a sociedade assim o quer, a partir de fundamentos normativos. Até os socialmente excluídos podem, de acordo com a mensagem normativa, ser reunidos e, portanto, ainda pertencem à ampla gama do "normal", dentro da qual um fato delituoso pode ser atribuído como culpável11. Ademais, a mensagem da prevenção geral da pena deve ser dirigida a todos os outros potenciais infratores, que se encontram em situações parecidas, mensagem essa que eles também devem levar em consideração, caso não queiram arriscar a grave desvantagem de serem punidos.

(2) A normatividade do normal mostra-se também pela sua aplicação nos casos individuais. Aparentemente, pelo fato de certas habilidades serem encontradas na maioria da população, inferimos uma norma que exige que os indivíduos se comportem

\footnotetext{
${ }^{9} U \mathrm{~m}$ argumento questionável diante das consequências esperadas para um agente com capacidade de culpabilidade (colocação em uma instituição psiquiátrica - $\S 63 \mathrm{StGB}$ ).

${ }^{10}$ Apud NK-Schild (nota. 2), $§ 20 \mathrm{Nm} 21$; Há também uma visão geral de toda a história da reforma.

${ }^{11}$ Com mais detalhes: Klaus Günther, Die Zuschreibung strafrechtlicher Verantwortlichkeit auf der Grundlage des Verstehens, in: Klaus Lüderssen (Org.), Aufgeklärte Kriminalpolitik oder Kampf gegendas Böse?, vol. 1: Legitimationen, Baden-Baden 1998, p. 319 ss.
} 
de acordo com essa habilidade. Grosseiramente formulado, tem-se que: se a maioria dos destinatários da norma, que se encontrem em situação de conflito e, ainda assim, possam abster-se de violar a norma, então o individuo também o pode fazer. Da média generalizada podemos alcançar uma obrigação individual.

É exatamente isso que Eduardo Kohlrausch formulou, já em 1910: “Assim, em todo julgamento, em que se atribui culpabilidade a um infrator, repousa uma generalização do caso, uma comparação entre o caso concreto ocorrido e um acontecimento normal, mas isso não significa nada além de um comportamento esperado e necessário" ${ }^{12}$. À parte da duvidosa legitimidade dessa inferência, do poder pelo dever - em que os infratores, como Kohlraush corretamente salientou, aprendem quando ouvem a exigência: "Você pode, porque você deve!" - isso em nada ajuda a responder a pergunta se o delinquente num caso particular era realmente livre para deixar de infringir a norma.

Tanto o lado empírico quanto o normativo da suposição generalizada de normalidade deixam claro que não são meras afirmações contra-fáticas. A capacidade de entendimento e a habilidade de autodeterminação são encontradas na maioria dos destinatários da norma, e geralmente são utilizadas pelos agentes, de tal modo que eles atuam de acordo com a lei, na maioria das vezes. Aqueles que pertencem a essa maioria, que têm essa capacidade e, ainda assim, violam bens jurídicos, são tratados de acordo com essa capacidade, como uma pessoa que não se utilizou de suas capacidades, como devia e podia. Daí decorre a legitimidade de se atribuir responsabilidade criminal. No entanto, essa pessoa pode contestar essa atribuição referindo-se a uma dessas condições excepcionais, das quais decorrem, porém, os fundamentos de exclusão da culpabilidade (irresponsabilidade penal, capacidade de culpabilidade e erro de proibição inevitável), que significam que esta é completa ou temporariamente incapaz de responder, vez que não tinha a capacidade de que é dotada a maioria das pessoas. Por outro lado, os motivos de exculpação (estado de necessidade exculpante, excesso de legítima defesa e colisão de deveres) não levam à exclusão dessa capacidade, uma vez que são circunstâncias que apenas dificultam a possibilidade de seguir a norma. Apesar dessas condições excepcionais levarem à

\footnotetext{
${ }^{12}$ Eduard Kohlrausch, Sollen und Können als Grundlagen der strafrechtlichen Zurechnung, in: Festgabe für Karl Güterbock, Berlin 1910, p. 3 e ss. (p. 25). Uma versão atual desses argumentos, pode ser encontrada em: Hans-Heinrich Jescheck/Thomas Weigend, Lehrbuch des Strafrechts Allgemeiner Teil, 5. ed. Berlin 1996, § 39 III.
} 
negação da culpabilidade, elas não decorrem do fundamento de que o autor, no momento do crime, sofria de uma completa falta de normalidade ${ }^{13}$.

\section{PRESSUPOSIÇÃO DE NORMALIDADE E LIVRE ARBÍTRIO}

Para o Direito Penal a pergunta crucial na controvérsia com a neurociência deveria ser a seguinte: É possível, a partir da maioria, distinguir as razões fáticas e normativas para o "normal" e, com base nas habilidades práticas médias, interpretar o sentido de livre arbítrio? Em outras palavras: as pessoas que possuem habilidades normais não são, em princípio, determinadas diferentemente do que aquelas que não têm essa habilidade? Na discussão da ciência do direito penal sobre essa pergunta, encontram-se posições tanto deterministas quanto indeterministas, assim como também agnósticas.

Von Liszt caracterizou a capacidade de imputabilidade como "determinabilidade normal" através de representações e motivos (por exemplo, valores religiosos ou morais, mas também por meio de ameaça de pena): "Assim, tem capacidade de culpabilidade toda pessoa mentalmente madura e sã, que tenha o entendimento sem perturbações. Desse modo, o conteúdo normal e a força motivadora normal compõem a essência da capacidade de culpabilidade"14. Portanto, para von Liszt, o imputável, em sua conduta, é tão determinado quanto o inimputável. A diferença está apenas na forma e maneira, uma vez que o imputável é determinado como normal, e o inimputável é diferente da vasta maioria da normalidade. O imputável pertence ao grupo de pessoas, que - através de valores, normas e ameaça de pena - pode ser causalmente determinado - e quando ele, em casos individuais, é determinado por uma razão mais forte a cometer um crime - constitui esse um fundamento para imputar-lhe um fato típico e puni-lo com finalidades preventivo-especiais ${ }^{15}$. Como muitos outros deterministas, Liszt também tem um argumento importante contra o indeterminismo, ou seja, a

\footnotetext{
${ }^{13}$ Finalmente, há também a possibilidade de mera diminuição da pena, como nos $\S \S 21,213,17$, p. 2,35 , parágrafo 1, p. 2 StGB e os motivos para aplicação da pena culpável do § 46 StGB. Para a distinção entre exculpantes e causas de justificação, cf.: Jescheck / Weigend (nota 10), § 43 Il; contrariamente Roxin (nota 2), § 19, Nm, p. 56. (Os oponentes dessa distinção confiam no fato de que em ambos os casos não é necessária uma punição por razões preventivas gerais).

${ }^{14}$ Franz v. Liszt, Lehrbuch des Deutschen Strafrechts, 13. ed. Berlin 1903, p. 163.

${ }^{15} \mathrm{~V}$. Liszt formulou em seu manual "A capacidade de imputabilidade criminal - uma réplica", ZStW 18 (1898), p. 229 e ss. (p. 258): "Também podemos dizer: esse criminoso é determinável pela ameaça de pena - embora ele de fato não tenha se determinado por ela, mas sim cometeu o crime. Queremos dizer que a maioria do resto das pessoas se deixa levar pela ameaça de pena e que essa pessoa não é essencialmente diferente das outras. Baseamos nosso prognóstico e valorizamos o julgamento nessa semelhança do criminoso com as outras pessoas".
} 
afirmação do livre arbítrio absoluto: Se a nossa conduta não fosse determinada por nada, se a liberdade fosse possível sempre como algo incondicionado, seria então apenas um espelho do acaso. Responsabilizar alguém pelo acaso, iria contra nossas intuições de forma muito mais ampla do que a pressuposição do determinismo.

Bem longe disso, o Tribunal Federal de Justiça, por outro lado, havia se aventurado na direção do indeterminismo com uma decisão sobre erro de proibição no ano de 1952. O fundamento da acusação repousava no fato de que "o homem é investido de uma autodeterminação livre, responsável e moral, portanto, é capaz de decidir entre o certo e o errado"16. Isso significa, que ele, no momento do fato, tinha a liberdade de agir de outra forma, de deixar de realizar a ação e seguir o caminho correto. Contudo, essa tentativa do Tribunal Superior, de determinar positivamente o conceito de culpabilidade do Direito Penal, não teve nenhuma consequência posterior. Os Tribunais penais ainda não conseguiram examinar, em cada caso individual, se as características do conceito de culpabilidade, mencionadas na definição, realmente se faziam presente no acusado. É improvável que isso seja possível, assim como é pouco provável que se tenha conhecimento de que o agente, no momento da ação delitiva, de fato, poderia ter agido de outra forma, sendo essa a objeção mais frequente contra a referida posição do Tribunal Federal (por exemplo Paul Bockelmann, Arthur Kufmann) 17. Com isso, de modo algum, colocou-se fim à controvérsia científica sobre o conceito de culpabilidade e sua relação com o livre arbítrio. A afirmação de que uma pessoa, em idênticas condições, em um determinado momento, poderia ter agido de outra forma do que efetivamente agiu, não apenas não pode ser provada, como também acaba se transformando em algo relegado ao acaso. Se alguém entender a "liberdade" como uma conduta sem causas ou sem condições, então não será possível fazer atribuições a essa pessoa por sua conduta, mesmo no sentido fraco, de que ela é causalmente responsável pela ação ${ }^{18}$.

\footnotetext{
${ }^{16}$ BGHSt 2, 194 (200).

${ }^{17}$ Paul Bockelmann, Willensfreiheit und Zurechnungsfähigkeit, ZStW 75 (1963), p. 372 ss.; Arthur Kaufmann, Das Schuldprinzip, Anhang, 2. ed. Heidelberg 1976, p. 263 e ss.; idem, Unzeitgemäße Betrachtungen zum Schuldgrundsatz im Strafrecht, JURA 1986, p. 225 e ss. Sobre a história crítica da recepção do julgamento BGH e seu desenvolvimento posterior na jurisprudência cf.: Ulfrid Neumann, Die Schuldlehre des Bundesgerichtshofs - Grundlagen, Schuldfähigkeit, Verbotsirrtum - , in: 50 Jahre Bundesgerichtshof - Festgabe aus der Wissenschaft, vol. IV, orgs. v. Claus Roxin/Gunter Widmaier, München 2000, p. 83 ss.

${ }^{18}$ Esse argumento desempenhou um papel central na análise da filosofia do Direito penal com o hegelianismo já no século XIX (incluindo Merkel vs. Hälschner); cf. Klaus Günther, Schuld und kommunikative Freiheit, Frankfurt am Main 2005, p. 14. A respeito da controvérsia filosófica sobre liberdade condicional e incondicional cf. em detalhes Peter Bieri, The Craft of Freedom, Munique / Viena 2001, p. 165.
} 
Diante dessas conclusões contraditórias, muitos recuam para uma posição agnóstica, tentando definir a culpabilidade criminal de forma aberta, tanto a posições deterministas, quanto a indeterministas. De acordo com Roxin, que expressamente define-se como agnóstico, "a culpa deve ser entendida como um atuar ilícito, apesar da responsabilidade normativa" ${ }^{19}$. Com isso a culpabilidade não é mais compreendida como a capacidade psíquica de uma pessoa de controlar a si mesma, mas sim ser psiquicamente capaz de responder às normas, de tal maneira que possa incorporá-las em sua capacidade de controle. Aqui, porém, novamente, nos encontramos diante do duvidoso argumento da força normativa da facticidade, quando Roxin assevera que essa qualidade de controle "é dada aos adultos saudáveis na maioria dos casos" 20. Aquele que está nessas condições será "tratado como livre" e essa é uma "concepção normativa (...) cujo valor social é independente dos problemas epistemológicos e científicos do livre arbítrio" ${ }^{21}$. A vantagem dessa posição é, obviamente, o esclarecimento de que a decisão sobre a culpabilidade e qual tipo de determinabilidade é válida como normal ou anormal, é uma decisão normativa, que é medida de acordo com os valores sociais de normalidade e pressuposição de normalidade. Seu valor, portanto, pode ser tão elevado quanto a profundidade com que seja marcada pela liberdade a autocompreensão social, assim como as instituições nela sejam fundadas. Esse argumento, porém, levanta uma importante objeção: para um determinista consequente, em qual valor social uma decisão normativamente justificada pela liberdade deve se fundar, já que restou comprovado pelos neurocientistas que ela é uma completa ilusão22.

Essa fraqueza argumentativa acabou finalmente levando alguns autores a substituir completamente qualquer insinuação de liberdade existente no conceito de culpabilidade, definindo-o de forma puramente normativa ou funcional ${ }^{23}$. Pode ser tido como culpado todo e qualquer delinquente cuja pena seja necessária para alcançar-se determinada finalidade social, seja para intimidar potenciais futuros infratores, seja para

\footnotetext{
${ }^{19}$ Roxin (Nota. 2), § $19 \mathrm{Nm} .36$.

${ }^{20}$ Idem.

${ }^{21}$ Idem., Nm. 37.

${ }^{22}$ Sobre essa objeção, cf. Michael Pauen, Illusion Freiheit? Mögliche und unmögliche Konsequenzen der Hirnforschung, 2. ed. Frankfurt am Main 2005, p. 235.

${ }^{23}$ Veja, por exemplo: Günther Jakobs, Strafrechtliche Schuld ohne Willensfreiheit, in: Dieter Henrich (org.), Aspekte der Freiheit, Regensburg 1982 p. 69 e ss. Mais recentemente, com as exigências políticocriminais das neurociências, tratando criticamente 'Individuum und Person' (nota. 2). Embora Jakobs permita que o discurso sobre "liberdade" (e até mesmo "liberdade de vontade") seja reutilizado, ele é exclusivamente no contexto de significado e atribuição constituído pelo sistema comunicativo da sociedade (Cf.: Jakobs, nota. 2, p. 257 e 261 ss.).
} 
restaurar ou reafirmar a confiança da comunidade na validade da norma ou na inviolabilidade do bem jurídico, afetadas pela prática delitiva. Aquele que, em condições internas ou externas normais, comete um delito, irrita todo aquele que atua de acordo com a lei, nas mesmas condições - e, desse modo, deve ser tratado como alguém individualmente responsável, devendo arcar sozinho com os custos dessa ação. Nesse contexto, esgota-se o significado da responsabilidade penal ou culpabilidade. Se e em que medida uma sociedade fica irritada pela violação do Direito, depende dos seus condicionamentos funcionais como sistema comunicativo e de suas decisões normativas. Que, por exemplo, a (inevitável) falta de conhecimento sobre a ilicitude de uma ação exclua a culpabilidade é uma decisão relativamente recente. Durante muitos séculos valeu a afirmação contrária, de que o desconhecimento da lei não afasta a aplicação da pena (error iuris nocet). O reconhecimento do erro de proibição como causa de exclusão da culpabilidade não decorreu, portanto, dos conhecimentos da neurociência, mas sim de considerações normativas, de que um fato praticado nessas condições não é lesivo para o funcionamento da sociedade moderna, uma vez que não há um senso comunicativo que possa irritar a sociedade. Da mesma forma, uma sociedade pode decidir em sentido contrário, que um delinquente, mesmo com uma forte carga pessoal, possa ser considerado culpado em uma situação de perigo, quando isso é necessário para o funcionamento da sociedade. Por exemplo, o Direito penal não reconhece o estado de necessidade exculpante nos casos em que determinada pessoa, como um soldado ou bombeiro, se comprometeu a suportar perigos graves ( $\$ 35$ (1) 125 p. 2 do Código Penal alemão) ou o excesso de legitima defesa somente é exculpante para as pessoas que tenham ultrapassado os limites da legítima defesa, sob o domínio de afetos socialmente aceitáveis, como o medo e o terror, mas não admite a exculpante para afetos não tolerados pela sociedade, como o ódio ou a ira.

Com essa dissociação da liberdade, certamente, chega-se ao ponto em que o conceito de culpabilidade é mantido apenas por conta de seu "valor social" ou sua funcionalidade social. Nesse sentido, Eduard Kohlrausch, em 1910, caracterizou a aplicação da insinuação da capacidade média dos indivíduos delinquentes, com a famosa frase, com a qual "a capacidade individual se torna (...) uma ficção necessária para o Estado" 24. O fundamento dessa ficção não está mais na liberdade da pessoa, mas sim na finalidade estatal e social e nas exigências funcionais, com a qual elas serão alcançadas e realizadas. Como essa ficção puramente orientada a fins, a noção de

${ }^{24}$ Kohlrausch (nota. 10), p. 26. 
culpabilidade fica mantida, mesmo que o comportamento humano seja totalmente determinado pela causalidade. Não é a liberdade que dá conteúdo à culpabilidade, mas sim a finalidade social. Contudo, Kohlrausch também declarou claramente o que isso significa para os delinquentes individuais: "O agente é sacrificado para o bem comum, ele tem que sofrer para atender esse interesse" 25 .

Enquanto isso, nessa posição, a questão não resolvida da liberdade acaba voltando como uma intrusa, pelo menos, em dois sentidos. No primeiro, a sociedade não pode "sacrificar" o delinquente para atender nenhuma finalidade. Desse modo, uma pessoa que mata por imprudência no trânsito deveria - para fins de intimidação - ser punida de forma mais severa que um homicídio doloso. A finalidade da pena, assim, deve manter uma proporcionalidade entre o fato e o grau de culpabilidade do autor. Aquele que, em uma situação difícil, mas ainda culpável, viola bens jurídicos alheios, deve ter uma pena menos severa do que aquele que, por exemplo, comete um crime por puro egoísmo. A proporcionalidade entre o fato, a culpabilidade e a pena, contudo, não pode ser determinada sem olhar-se para o grau de liberdade e do envolvimento interno do autor na ação ${ }^{26}$. O conceito de culpabilidade funciona, assim, ao mesmo tempo, também como limite normativo para a pena preventiva. Roxin atribui, portanto, ao conceito de culpabilidade não só o papel de uma ficção necessária para o Estado, mas sim um "pressuposto de garantia da liberdade" contra os excessos punitivos preventivos do Estado ${ }^{27}$.

A dependência do conceito de culpabilidade do seu valor social deixa, também, claro que a determinação de "se" e "como" se dá a culpabilidade é uma opção socialmente necessária. Trata-se de uma questão política que cabe ao legislativo decidir. Nesse caso, porém, seria necessário responder a pergunta que Roxin deixou de fazer, ou seja, a quem caberia estabelecer a distinção entre normal e desviado, com base em quais critérios, em quais foros e com base em quais procedimentos. Seguramente, existem várias respostas para essas perguntas, que poderiam ser divididas entre aquelas em que a liberdade se faz presente ou não, dependendo se a resposta é dada em um Estado autoritário, em uma sociedade de classes ou em um Estado Social e Democrático de Direito. Nesse sentido, von Liszt pôde asseverar, ainda

\footnotetext{
${ }^{25}$ Idem.

${ }^{26}$ Detalhes do exposto acima: Klaus Günther, Voluntary Action and Criminal Responsibility, in: Sabine Maasen/Wolfgang Prinz/Gerhard Roth (Org.), Voluntary Action. Brains, Minds, and Society, Oxford 2003, p. 263 e ss.

${ }^{27}$ Roxin (nota. 2), § 19 Nm. 49.
} 
no ano de 1898, que: "nós, a classe dominante, decidimos hoje quem deve ser punido ou não (...) nós declaramos hoje que as pessoas mentalmente enfermas são incapazes de serem punidas" ${ }^{28}$. Se o conceito penal de culpabilidade tem algum valor e qual valor seria esse, depende da sociedade e de seus valores. Se a liberdade pertence a esses valores, então o conceito de culpabilidade não poderá contradizê-lo. Dessa maneira, o conceito de culpabilidade reflete a auto-compreensão normativa da sociedade. Em uma democracia constitucional, fundada nos direitos humanos e fundamentais, os cidadãos e cidadãs ostentam tanto direitos subjetivos de liberdade, quanto direitos políticos de participação, com os quais se dá a liberdade de organização. Esses direitos não poderiam ser concedidos reciprocamente, caso não fosse atribuída, ao mesmo tempo, aquela visão de normalidade de entendimento e capacidade de autodeterminação, com base na qual é possível solicitar, compreender, rejeitar, adotar e agir de acordo com razões. No entanto, eles se contradizem quando, de um lado, se atribuem normalidade (por exemplo, na liberdade contratual e na liberdade de expressão) e de outro (no conceito de culpabilidade penal) a negam novamente. Portanto, a atribuição de normalidade não deve ser uma mera expressão da auto-compreensão fática de uma classe dominante, para a qual o delinquente individual teria que se sacrificar por meio da pena, mas sim deve tornar-se objeto de críticas abertas e de justificação de todos os afetados - em que esses atingidos devem utilizar essa atribuição de normalidade, quando ingressam em um discurso público ${ }^{29}$. Entendimento e capacidade de autodeterminação são, portanto, ambos, tanto temas quanto meios desse debate público de justificação. Conclusão: a normalidade de entendimento e capacidade de autodeterminação, pressuposta com a atribuição de culpabilidade, assim como o determinação de quais condições excepcionais da atribuição de culpabilidade, em qual extensão e com quais consequências, somente pode ser o resultado de um debate crítico público e de justificações.

\section{TRÊS OPÇÕES PARA TRATAR DAS HIPÓTESES DAS NEUROCIÊNCIAS}

Conforme os exemplos acima demonstraram, um conceito de culpabilidade orientado pela liberdade não pode se afastar de uma posição determinista ou mesmo

\footnotetext{
${ }^{28} \mathrm{v}$. Liszt, Die strafrechtliche Zurechnungsfähigkeit (nota. 14), p. 256.

${ }^{29}$ Veja também: Klaus Günther, Schuld und kommunikative Freiheit (nota. 16); idem, Individuelle Zurechnung im demokratischen Verfassungsstaat, in: Jahrbuch f. Recht u. Ethik (2) 1994, p. 143 ss.; Urs Kindhäuser, Rechtstreue als Schuldkategorie, ZStW 107 (1995), p. 701 ss.
} 
agnóstica. Nessa situação, resta para o Direito penal e para as Ciências Penais essencialmente três opções para lidar com as hipóteses estritamente deterministas e com as conclusões das neurociências. Essas, também no passado, sempre foram praticadas, em vários graus, em maior ou menor alcance de consequência, em controvérsias similares com a posição determinista:

(i) Deixa-se tudo como está. No máximo revisa-se a configuração do $\S 20$ StGB, na parte em que estabelece os critérios para o reconhecimento de doenças que excluam a capacidade de entendimento e de autodeterminação, de acordo com os conhecimentos mais recentes da neurociência e outras ciências naturais sobre 0 homem. Entretanto, o Direito penal não se dissocia da quotidiana de atribuição prática de liberdade e responsabilidade, como já ocorre em nossa sociedade de acordo com o modelo de regra-exceção, apresentado no início, e utiliza a linguagem de atribuição cotidiana da psicologia, independentemente se nós somos determinados ou não. $O$ Direito penal apenas refina e formaliza os critérios de atribuição e os procedimentos nos quais será decidida a culpa do delinquente. A favor dessa opção pesam o fato de que ela encontra-se em consonância com a autocompreensão fática da sociedade e com as estruturas, instituições e princípios básicos, que são constitutivos para uma sociedade justa e equitativa de cidadãos livres e iguais (direitos constitucionais e fundamentais, democracia representativa, Poder Judiciário independente, direito de propriedade e liberdade contratual). As controvérsias sobre o determinismo (da física sobre a psicologia até a biologia), que têm se repetido, pelo menos, desde o iluminismo, com cada nova mudança de paradigma, somente foi capaz de alterar a periferia do Direito penal, nunca o seu núcleo. No entanto, essa opção (que, na verdade, é uma não opção) tem uma desvantagem: ela depende de que a auto-compreensão social, com sua prática quotidiana de atribuição, não se deixe impressionar pelas proposições da neurociência. Nesse exato momento, porém, os seus mais proeminentes representantes almejam justamente o oposto, eles explicitamente pretendem criar uma nova imagem do ser humano ${ }^{30}$. Desse modo, não é por acaso que eles escolheram a culpabilidade penal como caso-modelo para essa pretensa revisão da concepção humana.

(2) Ingressa-se na controvérsia entre neurocientistas e filósofos sobre determinismo e indeterminismo e, eventualmente, revisa-se o conceito de culpabilidade

\footnotetext{
${ }^{30}$ Veja também, dentre outros, 'Das Manifest. Elf führende Neurowissenschaftler über Gegenwart und Zukunft der Hirnforschung', Gehirn und Geist 3/2004, p. 30-37.
} 
criminal. Com isso, demonstra-se que a controvérsia sobre a concepção penal de pressuposição de normalidade reflete na controvérsia filosófica sobre o livre arbítrio ${ }^{31}$. Aqui encontram-se, novamente, várias versões sobre um determinismo fraco ou forte, um indeterminismo e um determinismo aparentemente compatível com o conceito de livre arbítrio. Um determinismo forte nos levaria a desistir de nossas concepções quotidianas de livre autocompreensão e assim também das nossas estruturas, instituições e princípios baseados nela (e, consequentemente, desistir não apenas do Direito Penal, mas de todo o Direito, em geral!). Mesmo se quisermos nos manter sob o impacto das pesquisas dos neurocientistas, ainda assim continua questionável: se nós poderíamos objetificar nossas vivas relações sociais, simbólicas e comunicativas (que incluem os neurocientistas, que, em seu papel orientado pela busca da verdade, também fazem parte da comunidade científica); se nós poderíamos, de forma duradora, nos entender (!) como objetos exclusivamente físicos, que se observam e se comunicam apenas em uma linguagem de observador, sem que nos tornemos incompreensíveis como seres agentes, questionadores ou aprendizes ${ }^{32}$. Por outro lado, o indeterminismo deve, ou comprovar que existe uma espécie de gap no mundo causalmente fechado da natureza, no qual uma ação pode valer como livre (ou seja, sem ter a ver com uma causa) ${ }^{33}$. Nesse caso, porém, a liberdade não é mais delimitada pelo acaso - e no Direito ninguém é responsável pelo acaso. A alternativa seria uma concepção metafísica de liberdade completamente desvinculada da causalidade natural, mas com a qual não é possível explicar como o mundo do espírito livre pode causar algo no mundo da natureza, sem se tornar a própria natureza. Desse modo, a mais promissora tentativa parece ser, no momento, aquela que ninguém nega. Que vivemos num mundo causalmente fechado, um mundo determinado, mas descrever a forma e a maneira com que o homem se determina, através do seu próprio espírito, é muito mais sofisticado e complexo do que fazem os neurocientistas. A determinação do normal, que, com seu modelo de regra-exceção, o Direito penal fundamenta a atribuição de culpabilidade, aqui é decifrada com maior detalhe do que em von Liszt e seus sucessores. Essencialmente,

\footnotetext{
${ }^{31}$ Veja acima de todas as contribuições para a filosofia da mente. Em resumo e introdutório: Michael Pauen, Grundprobleme der Philosophie des Geistes, 2. ed. Frankfurt/Main 2001; Ansgar Beckermann, Analytische Einführung in die Philosophie des Geistes, 2. ed. Berlin/New York 2001.

${ }^{32}$ Lutz Wingert, Grenzen der naturalistischen Selbstobjektivierung, in: Dieter Sturma (org.), Philosophie und Neurowisssenschaften, Frankfurt am Main 2006, p. 240 e ss.

${ }^{33}$ Pelo menos como uma hipótese (com a consequência de um ônus da prova das neurociências e a preservação do conceito de culpabilidade): Klaus Lüderssen, Das Subjekt zwischen Metaphysik und Empirie - Einfluss der modernen Hirnforschung auf das Strafrecht?, in: Aktuelle Anthropologie, Jubiläumsband der wissenschaftlichen Gesellschaft der Johann Wolfgang Goethe-Universität Frankfurt am Main/ Stuttgart 2005, p. 187 e ss.
} 
trata-se de uma presunção, de que uma decisão livre é determinada por razões, que, também, são realizadas por meio de um modelo de causa e efeito, mas que não podem nem se reduzir a razões, sem deixar rastros, nem constituem um mero epifenômeno. $A$ relação causal com o comportamento é assim como a relação entre fumaça e fogo. Essa pressuposição é ditada parcialmente de forma controversa, em diversas variantes. Desse modo, a liberdade deveria ser no sentido de que uma pessoa pode seguir suas intenções a longo prazo e que pode superar fortes impulsos e hábitos profundamente enraizados. Uma pessoa que tal não tem suas ações completamente comprometidas por situações de estímulo imediato e, de tal maneira, se autodetermina e se controla, a ponto de ser responsável por suas próprias ações ${ }^{34}$. Outras propostas visam os diferentes contextos, em que explicações naturalistas por leis causais, por um lado, e a atribuição de responsabilidade das pessoas agentes, por outro lado, desempenham um papel. Esses jogos de linguagem podem coexistir, pois cumprem funções diferentes ${ }^{35}$. É claro que ainda é controverso se a específica natureza das razões não se perde, caso a razão seja utilizada apenas como uma forma complexa de causa. O cérebro, possivelmente, precisa ser motivado por uma programação cultural para poder expressar as razões. Mas as pessoas se movimentam no espaço das razões de forma diferente do que o cérebro nas relações de causa e efeito ${ }^{36}$. De novo, outras tentativas nessa direção se fundamentam na inevitabilidade de o sujeito experimentar a liberdade, para a qual existem razões epistemológicas e neurobiológicas. Quais consequências isso terá para o conceito penal de culpabilidade é algo que ainda resta ser descoberto. Mas, provavelmente, não será nada que demandará uma revisão fundamental ${ }^{37}$.

(3) Das hipóteses do determinismo estrito dos neurocientistas, extrai-se a consequência radical da abolição do conceito penal de culpabilidade, substituindo-o por categorias da neurociência e, consequentemente, substituindo a pena por medidas protetivas da sociedade contra indivíduos perigosos.

\footnotetext{
${ }^{34} \mathrm{Da}$ perspectiva da psicologia cognitiva: Thomas Goschke, Vom freien Willen zur Selbstdetermination. Kognitive und volitionale Mechanismen der intentionalen Handlungssteuerung, in: Psychologische Rundschau 2004.

${ }^{35}$ Marcus Willaschek, Der freie Wille - Eine Tatsache des praktischen Lebens, Forschung Frankfurt 4/2005 (Geist und Gehirn), p. 51 e ss.

${ }^{36}$ Veja também Lutz Wingert, Gründe zählen. Über einige Schwierigkeiten des Bionaturalismus, in: Christian Geyer (Org.), Hirnforschung und Willensfreiheit, Frankfurt am Main 2004, p. 194 ss; Jürgen Habermas, Freiheit und Determinismus, Deutsche Zeitschrift für Philosophie 2005, p. 187 ss.; Klaus Günther, Grund, der sich begründet. Oder: Was es heißt, eine Person zu sein, Neue Rundschau 2003, p. 66 ss.

${ }^{37}$ Para a última posição da inevitabilidade da experiência da liberdade e suas consequências para o conceito de culpabilidade, cf.: Burkhardt (nota. 2).
} 


\section{CONSEQUÊNCIAS DECORRENTES DA HIPÓTESE DO DETERMINISMO} ESTRITO

A terceira consequência, porém, é a mais temida pelos neurocientistas ${ }^{38}$. A maioria deles se enxerga como representantes de um humanismo iluminista, que pretende libertar os seres humanos das pesadas consequências de uma ilusão, de forma similar aos que combateram os julgamentos das bruxas no início do período moderno. Para eles, uma acusação fundada no livre arbítrio seria tão equivocada quanto a crença de que determinadas pessoas estariam possuídas por poderes malignos, a fim de causar danos ao mundo. A pena apareceria, assim, tão injusta quanto a execução na fogueira. Obviamente, a luta contra os julgamentos de bruxas não foi provavelmente liderada apenas pelos primeiros cientistas, mas sim principalmente por juristas, que duvidavam da justiça dessa prática. Mais tarde, também, sempre foram os juristas (embora muitas vezes sob o escrutínio de um público crítico e esclarecido) que lutaram contra as ilusões e suposições não comprovadas no Direito penal. Nesse aspecto, os neurocientistas e a Ciência Penal crítica vem se unindo desde o iluminismo. $\mathrm{O} \S 20$ StGB está sempre sob a condição de que descobertas recentes das ciências médicas não exijam uma revisão das suposições com as quais assumimos a liberdade onde não há.

Essa crítica contínua, contra uma visão tacanha do Direito Penal, vive, porém, inspirada pela convicção de que somente ações ilícitas livres merecem a imposição de uma pena e, de tal maneira, é injusto culpar e punir uma pessoa que não tinha mais essa liberdade no exato momento do fato. Isso se aplica também às teorias de sociologia e da psicologia criminal, que, nos anos sessenta e setenta, começaram a esclarecer que o crime decorria de inequidades sociais e de distúrbios narcísicos do desenvolvimento na primeira infância. Mesmo essas teorias, dificilmente se opõem à um determinismo social ou psicológico, uma vez que o seu principal objetivo é precisamente reconhecer e alterar as referidas condições sociais e psicológicas, que diminuem, restringem ou distorcem a liberdade. Não é por acaso que as atuais pesquisas sobre o cérebro vêm acompanhadas de uma política criminal, que busca as causas e fundamentos do crime apenas nos delinquentes, opondo-se veementemente

${ }^{38}$ Por exemplo, Gerhard Roth em uma disputa com Klaus Günther, Bild der wissenschaft, Heft 3/2005. 
contra as explicações das ciências sociais e psicológicas ${ }^{39}$. Finalmente, por um bom motivo, também, é possível negar que a punição no sentido de uma imposição estatal de males e dores pode transmitir os significados pretendidos pela política criminal e servir a propósitos ${ }^{40}$. Mesmo essa crítica da pena argumenta, em nome da liberdade e da justiça, que elas seriam violadas, caso a punição não fosse justificável. O humanismo iluminista dos neurocientistas, no entanto, vai além: a própria convicção é questionada.

Aqui os caminhos dos penalistas críticos e dos neurocientistas são separados. Se a concepção de liberdade do próprio homem fosse abandonada, não seria mais possível punir. Se a punição não fosse mais baseada na culpa, sobraria apenas a finalidade de proteção da sociedade como finalidade da pena. Seria necessário então, no lugar da pena, colocar-se medidas de segurança (Sicherungsverwahrung), como ocorre hoje para os reincidentes perigosos, que atualmente pode, inclusive, ser aplicada após o cumprimento da pena ${ }^{41}$. Ademais, a necessidade de medida de proteção à sociedade pode ser bastante distinta, dependendo da situação local e do clima político. Dependendo de quanto a população se sinta ameaçada por um criminoso, a pena teria que ser maior ou menor. Um pequeno crime, cometido por um criminoso muito perigoso, exigiria uma ação mais intensa do que um crime grave cometido por um criminoso inofensivo. Além disso, a população pode desenvolver necessidades de proteção cuja legitimidade pode ser altamente controversa ou altamente questionável. Não faz muito tempo, na ex-União Soviética, dissidentes políticos foram processados e considerados culpados, tendo sido internados como "loucos" em uma instituição psiquiátrica42. A categoria de periculosidade se enquadra em um criminoso cuja ofensa viola uma lei criminal racista? Um presidente do conselho administrativo, que tenha se envolvido significativamente em uma decisão sobre um alto pagamento de indenização à diretoria executiva de uma empresa, em negociações para venda e, portanto, viole um passivo patrimonial legalmente indeterminado e controverso de acordo com o $\$ 266 \mathrm{StGB}$ (infidelidade), caso condenado, deveria ser tratado como perigoso e eventualmente ser submetido a um diagnóstico e terapia neurológicos?

\footnotetext{
${ }^{39}$ Sobre o tema, cf.: Karl-Ludwig Kunz, Krimi;nologie, 3. ed. Bern 2001, § 21. Sobre a polêmica contra o iluminismo das ciências Sociais, compare: Jerome H. Barkow/Leda Cosmides/John Tooby (org.), The Adapted Mind - Evolutionary Psychology and the Generation of Culture, New York/Oxford 1992.

${ }^{40}$ Klaus Günther, Kritik der Strafe I, West End - Neue Zeitschrift für Sozialforschung 2004, p. 117 e ss.

${ }^{41}$ Nota dos tradutores: As medidas de segurança pós-delitivas (Sicherungsverwahrung) foram declaradas constitucionais pela Corte Constitucional alemã (BverfG 2 BvR 2029/01 - 05 de fevereiro de 2004). Sem embargo, posteriormente, a medida foi declarada em desacordo com a Convenção Europeia dos Direitos Humanos pelo Tribunal Europeu dos Direitos Humanos (Mücke v Germany, Application no. 19359/04 - 12 de dezembro de 2009).

${ }^{42}$ Cf.: sobre o tema o filme "Gorki Park" de Michael Apted.
} 
No contexto de uma visão determinista do mundo, porém, a questão da legitimidade da necessidade de proteção já não pode mais ser levantada. O público em geral não pode fundar a finalidade da pena, nem a seleção de indivíduos perigosos que devem ser punidos, numa concepção humanitária. Quando a pena não se fundamenta mais na proteção da liberdade legalmente assegurada, qual finalidade então resta ao Direito penal? Presumivelmente, nem se deve falar em "finalidades", na medida em que isso implique em uma decisão autodeterminada das pessoas. Em vez disso, sobraria apenas o puro interesse de sobrevivência da maioria contra uma minoria (mais precisamente: uma maioria dos cérebros contra uma minoria de cérebros). O que vale como uma conduta punível depende de qual grupo prevaleceu em uma determinada população de pessoas (cérebros). A pena ou uma medida de segurança contra cérebros perigosos seria então apenas um meio na luta pela existência. Então, seria justo fazer o que beneficia o grupo dominante, protegendo-o. Justa seria a lei do mais forte. Isso, pelo menos desde Platão, é considerado precisamente o oposto de Justiça ${ }^{43}$. 0 humanismo proposto pelos neurocientistas críticos do Direito penal acabou provandose, ele mesmo, uma ilusão.

\section{UM PANORAMA RESUMIDO: O CONCEITO DE CULPA PENAL, NUM DIREITO PENAL PÓS-PREVENTIVISTA}

Aparentemente, o Direito penal - mesmo diante dos mais recentes desafios que Ihes são impostos pelas novas pesquisas, estritamente deterministas, sobre o cérebro e apesar das anunciadas revisões fundamentais da nossa concepção sobre o ser humano no Direito penal e na práxis do Sistema de Justiça Criminal - não mudará muito. Possivelmente, toda essa controvérsia cairá no silêncio por si mesma, sem que seja possível identificar, ao seu final, qual dos lados apresentou o argumento vencedor. $O$ Direito penal atual encontra-se em um acelerado processo de mudança, que nada tem a ver com os argumentos dos neurocientistas, mas sim com o interesse político-criminal em segurança. A partir dessa perspectiva, o conceito de culpabilidade penal se tornará obsoleto, uma vez que o delinquente será configurado tão somente a partir do aspecto de sua periculosidade para os interesses de uma maioria que pode desfrutar das suas liberdades econômicas.

\footnotetext{
${ }^{43}$ Veja, por exemplo, Platão, Gorgias, 482d ss., in: Platon, Sämtliche Werke, vol. II, Frankfurt am Main 1991, p. 287 e ss.
} 
O combate do Poder Legislativo contra a criminalidade organizada e econômica, contra os delitos sexuais graves e, mais recentemente, contra o terrorismo internacional deslocou o equilíbrio do direito estatal entre liberdade e seguridade em direção a este último. O Direito penal exerce apenas um papel secundário na arquitetura da segurança Estatal, que tem se tornado, cada vez mais, global ${ }^{44}$. Alguns exemplos disso são 0 emprego de métodos de inteligência na persecução penal (agentes infiltrados e informantes, pequenos e grandes intervenções de espionagem), a atuação funcional conjunta entre os agentes de persecução penal, policiais e autoridades militares agindo em concurso com equipes transnacionais de nível intergovernamental, a criminalização de atos preparatórios de simples colocações em perigo abstrato de bens jurídicos (v.g. $\S \S 129 a$ e b do Código Penal alemão), na atuação reativa da expansão da detenção preventiva até posterior possibilidade da aplicação de medidas adicionais. O Estado de Bem Estar Social, orientado preventivamente, que limitava o Direito Penal com o princípio da culpabilidade, transformou-se em um Direito penal pós-preventivo, exclusivamente focado na seguridade e no sistema global de proteção ${ }^{45}$.

O Direito penal pós-preventivo excluiu os delinquentes da tradicional prática de imputação, que pressupõe conhecimento e capacidade de domínio e que somente de maneira excepcional era afastada. A distinção entre a determinação normal e anormal da conduta tornou-se obsoleta. A luta contra os perigos situa-se muito além dessas distinções. O Direito Penal até aqui podia confiar no cumprimento da norma pela maioria dos seus destinatários e na sua habilidade de conhecimento e controle. No entanto, uma vez violado o bem jurídico, era possível atribuir a responsabilidade com base em fundamentos normais, com base na pretensão de validade do Direito. Caso a pessoa afetada por essa atribuição não pudesse afastá-la com base em um argumento de que houve uma situação excepcional, o Direito penal - em nome da maioria "normal", na qual estava incluído o delinquente - poderia responsabilizá-lo, uma vez que ele, com base no seu conhecimento e capacidade de domínio, rechaçou o Direito reconhecido, da mesma forma que todos esperam um dos outros. A "culpabilidade" é uma categoria que pode ser atribuída "ex post". No entanto, a luta preventiva contra perigos assumiu o seu lugar. E ela opera numa perspectiva "ex ante", buscando encontrar o ponto de partida o mais cedo possível para intervir, num mecanismo de causa e efeito, sem o qual, de outro

\footnotetext{
${ }^{44}$ Cf.: Klaus Günther, World Citizens between Freedom and Security, in: Constellations - An International Journal of Critical and Democratic Theory 12 (2005), p. 379 ss.; Günter Frankenberg, Kritik des Bekämpfungsrechts, KJ 2005, p. 370 ss.

${ }^{45}$ Peter-Alexis Albrecht, Kriminologie - Eine Grundlegung zum Strafrecht, 3. ed. München 2005, § 6 D.
} 
modo, provavelmente ocorreria um dano. Desse modo, não se trata mais de verificar se está presente uma ação humana culpável, já que pode ser demasiadamente tarde. Para garantir a segurança, é necessária a intervenção mais antecipada possível - como, por exemplo, por meio de um agente infiltrado que, como agente provocatio, testa as pessoas como num experimento de laboratório, se com ele se põe uma questão de perigo relevante à segurança ou por meio de um especialista em "tortura salvadora", que pressiona pessoas com o uso de efeitos causais como material de informação, para evitar perigos ameaçadores.

Caso a pessoa seja vista apenas como uma potencial fonte de perigo, que deve ficar sob observação estatal, então interessam todos os controladores de comportamento que sejam determinantes, dos quais seja possível prognosticar potenciais perigos. Essa é a lógica da detenção de segurança. Ela não confia mais na habilidade das pessoas de conhecer e controlar seus comportamentos, cujo uso equivocado também é a elas atribuído. Mas sim em indicadores que reconhecem, ou pelo menos suspeitam, de comportamentos perigosos que vão além da capacidade de compreender e dominar a própria conduta. O indivíduo perigoso é considerado apenas como um complexo de um sistema de relações causais propensas ao risco, no qual o Estado intervém com ações causais de combate ao perigo, principalmente por meio do simples bloqueio, com o objetivo de proteger a população contra futuros delitos. Esse processo não é levado a cabo apenas pelo Estado, mas também por uma larga maioria de indivíduos que acredita que sua forma de vida livre encontra-se ameaçada por indivíduos e organizações perigosas. Jakobs caracterizou essa despersonalização dos (potenciais) delinquentes como "Direito Penal do Inimigo" 46. Em contraposição ao Direito Penal do cidadão, em que o delinquente é tratado como pessoa, o inimigo é interceptado por medidas penais com antecedência e "enfrentado por conta de sua periculosidade" 47. A qualidade pessoal do cidadão decorre precisamente disso, ele "orienta-se pelo lícito e ilícito" e essa expectativa também é cognitivamente fundamentada, com base na qual em grande medida ele se comporta. Uma única violação da norma aparece, portanto, apenas como uma falha que pode ser atribuída à culpabilidade ${ }^{48}$. Esses são os, acima

\footnotetext{
${ }^{46}$ Günther Jakobs, Bürgerstrafrecht und Feindstrafrecht, in: Yiu-hsiu Hsu (Org.), Foundations and Limits of Criminal Law and Criminal Procedure, o.O. 2003, p. 41 ss. Aqui, interessa apenas o diagnóstico de Jakob sobre o Direito Penal do Inimigo, e não a controvérsia, que leva à sua observação de que o termo: "não é, em princípio, pejorativo" (ibid., p. 50), assim como o debate sobre se o Direito Penal do Inimigo é uma terapia justificada.

${ }^{47}$ Ibid., p. 53.

${ }^{48}$ Ibid., p. 50.
} 
explicados, componentes fáticos e normativos da pressuposição de normalidade e que constituem o conceito de culpabilidade. Eles são negados ao inimigo, ele não é reconhecido como pessoa livre.

No fim, pode ser uma surpresa que os neurocientistas, com sua proposta políticocriminal de abolição do conceito de culpabilidade penal, tenham apenas secundado a transformação do Direito penal do cidadão em um Direito penal do inimigo. Desde distintas perspectivas, a revisão neurocientífica da concepção de um ser humano livre e a moderna política criminal - quase política de segurança - chegam à mesma conclusão: o delinqüente não deve ser tratado como uma pessoa dotada de liberdade, discernimento e controle, mas como um conjunto de causas e efeitos sobre os quais o Estado, por sua vez, deve intervir causalmente, para obter determinados resultados. E é uma trágica ironia, cientificamente indecifrável, que os neurocientistas apresentem esse resultado de maneira humilde e o defendam em nome de um tratamento mais humano para os criminosos. 